\title{
Correction to: Combined microsurgical fluorescence for optimizing resection in refractory empyema and cerebritis
}

\author{
Carlos Sánchez Fernández ${ }^{1}$ - Bernardino Choque Cuba ${ }^{2}$ - Mónica Rivero-Garvía ${ }^{3}$ - Francisco de \\ Borja Arteaga Romero ${ }^{3}$. Javier Márquez Rivas ${ }^{3,4}$
}

Published online: 20 July 2020

(C) Springer-Verlag GmbH Germany, part of Springer Nature 2020

\section{Correction to: Child's Nervous System. \\ https://doi.org/10.1007/s00381-020-04762-9}

The original version of this article unfortunately contained an error. The corresponding author did not notice that one of the co-authors "Javier Márquez Márquez Rivas" was incorrectly presented. The correct name is "Javier Márquez Rivas". Given in this article is the corrected author name.

The original article has been corrected.

Publisher's note Springer Nature remains neutral with regard to jurisdictional claims in published maps and institutional affiliations.

The online version of the original article can be found at https://doi.org/ 10.1007/s00381-020-04762-9

\footnotetext{
Carlos Sánchez Fernández carlos_san_fer@hotmail.com

1 Department of Neurosurgery, University Clinical Hospital of Valladolid, Ramón y Cajal 3, St., 47005 Valladolid, Valladolid, Spain

2 Department of Neurosurgery, University Hospital of Getafe, Getafe, Madrid, Spain

3 Department of Neurosurgery, University Hospital Vírgen del Rocío, Sevilla, Sevilla, Spain

4 Center for Advanced Neurology, Sevilla, Sevilla, Spain
} 